\title{
Establishing A Mexico Service Learning Program: \\ Changing Cultural Perceptions, Building Relationships And Taking Risks
}

Kim Riordan, (E-mail: kriordan@d.umn.edu), University of Minnesota, Duluth Molly Minkkinen, (E-mail: mminkkin@d.umn.edu), University of Minnesota, Duluth Raquel Dominguez Mora, (E-mail: raqueldmz@yahoo.com.mx), Centro Universitario de la Costa

\begin{abstract}
This article describes the shared experience of three university professors, two from the United States and one from Mexico. While it began by chance, this experience has become a life-altering journey. It has forced the authors to question their own cultural competencies, and demanded that they take risks and move beyond the comfort and security of that which is familiar. It has proven to be the most gratifying of experiences. "We fell in love with a culture that embraced us beyond what we felt we deserved. Most significantly, we have broadened our circle of professional colleagues to include international peers".
\end{abstract}

\section{INTRODUCTION}

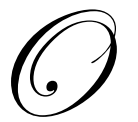

n many levels, this experience has changed the course of our lives. It has provided us with new friendships and international colleagues. It has afforded us a chance to grow - personally, professionally and culturally. More than anything, the experience has been a way for us to engage our students in becoming more aware of international issues, more culturally competent and more confident in their own ability to navigate in the world as global citizens. "Field experiences in diverse settings can optimally serve to heighten pre-service teachers' awareness of cultural, linguistic and learning difference among young children, and become the stimulus for open and difficult discussion that leads to new learning and reflective practice" (Wolfe \& Falk-Ross, 2002, p. 158). Students in teacher preparation programs who are presented with opportunities to experience life outside of their comfort zone are able to describe increased confidence in their ability to plan multicultural instruction, examine curriculum for bias, and have an increased sensitivity to students who are English language learners (Wilhelm, Cowart, Hume \& Rademacher, 1996).

Each society is responsible for transmitting knowledge. The transmission of knowledge, skills and dispositions falls to the educators who work with students. As our awareness grew of the changing demographics in the classrooms our students would be teaching in, the absolute certainty that we needed to do more demanded our attention. Of particular concern is the growing resistance to attempts to explore antiracism in teacher education programs, even in view of the increasingly diverse populations teachers will find themselves working in. Case and Hemmings (2005) describe a study that documents the phenomenon of distancing, in which young, white, lower to middle class education students tend to distance themselves from the antiracism curriculum, and instead adopt strategies that disallow self-reflection on these critical issues. These future educators, who interestingly mirror the public school's teacher population, will likely carry with them into their careers stereotypes and assumptions of the students they will be working with. These distancing strategies of university education students included silence, social disassociation, and separation from responsibility. The authors (Case \& Hemmings, 2005) further suggest that one way to ameliorate this resistance is to include students in discussions/problem solving on how to participate (with people of color) in activities related to social action. First though, we needed to learn the lessons ourselves. 


\section{KIM \& MOLLY}

Our story begins at a Clute Research Institute Conference we attended in Puerto Vallarta, Mexico in March 2005. A side tour, arranged by the conference coordinators, offered an opportunity to travel to a public school in order to tour the facility, meet with the educators there, and observe the students. As the tour bus pulled up to the locked iron gates of the Mexican public school, our expectations about Mexican children, living in economic poverty, and leading bereft lives were reinforced. A guard guided us through the gates. We were certain that sad children would meet us as we entered. We got off of that tour bus with gifts in hand - money in envelopes and a backpack full of books to donate. Along with our tangible items, we were also weighted down with assumptions and naiveté.

It may have been the heat, or the winding roads that the tour bus followed, but at some point mid way through our school tour one of our own children became ill. The experience of vomiting in front of a schoolyard full of children paled in comparison to what she found when she entered el baño. The trip into the bathroom was more about what was not there than what was - little more than a trickle of water in the sinks, no hand soap, stools without seats, and no toilet tissue or paper towels. The reality assaulted our preconceived notion that even in economic poverty children are afforded toilet seats, toilet paper and soap and water to clean their hands. Upon realizing what was happening the principal dashed to the cafeteria. He came back, offering a stack of table napkins. We later speculated that those napkins were likely not easily come by, yet perfectly suited to meet the immediate needs of an embarrassed American youngster.

After stabilizing both the emotional and physical needs of a motion sick child we began focusing on the environment before us. We found ourselves standing in the middle of a schoolyard, surrounded by a locked iron gate. The children were out of class for lunch/recess. There were at least 100 children running, chasing after one another and yelling. Many of the children were carrying tortillas and bags of red juice. There were no lunch tables, no hot trays full of food choices - just a small barred window in a cement block wall where a woman sat handing out tortillas and bags of juice. Other children were huddled in groups looking at the crowd of strangers with looks of anticipation. (They seemed to know we were not empty handed). Many eagerly spoke English to us. One little boy, fluent in English, talked with us and told us he had come from the United States - had been born there, but his parents had returned to Mexico to live. Interesting, we thought. We have come to understand that the children likely viewed us with simple curiosity (no different than children in the United States might view visitors who look different than they do-showing up in the middle of their school yard-in the middle of their school day).

Another of the girls in our party pointed out that the children did not have any toys in their schoolyard. There were no balls, hula-hoops, or jump ropes. She was dismayed by what she perceived to be a total lack of resources. As we watched the children play, we noticed child play that was cooperative. There were no "playground aids" redirecting the children at the rate one sees in the United States. The children were engaged in social play that involved a great deal of both verbal and physical interaction. This play included hugging and prosocial touch by both genders.

As we stood in the courtyard of the school we were struck with feelings of voyeurism. We had come to the school with a predetermined idea of how we were going to "help" the children by bringing a backpack, books, paper, markers, and a small amount of money. What we saw were children who were not in need of what we thought of as school necessities (paper, backpacks, and cash); they were in need of basic supplies such as toilet paper, clean water, and soap. As we stood, feeling ignorant and helpless, one of us asked the school administrators what they "really" needed. One replied, "We need you to come back and teach our children English". This ability affords Mexican children the opportunity to work in the tourist industry when they are older.

The idea that what the school most needed was assistance to teach children English created dissonance in our understanding about working with another culture. As university professors we were not interested in creating a missionary approach to our support of Mexican schools (i.e. we'll come down here and tell you what you need). Instead, we believed it was important to support and preserve the existing culture, language being the center of the culture. It called into question (again and again) our motivation to do this work-who did we think we were? What 
did we (really) have to offer? Could we make a difference AND do no harm? It began our quest to understand the inequities in a society seemingly different from ours, and yet facing many of the same systemic problems of inequity and social injustice. How much had we, as Americans, contributed to the apparent economic poverty in Mexico? We wanted to know more about how free trade laws had impacted the economic potential of communities. What were the political and economic consequences for decisions our country had made that we were not even aware of prior to our journey south. Some of the last words from the principal that day were, "Don't remember us for what we didn't have".

As we left the school, and the iron gates closed behind us, we began to talk about what we had just seen. Our heads were filled with ideas about what we could do, how we could do it...How WERE we going to do it? On that day, in the tour bus on the winding roads, we came to an understanding that included the absolute commitment that we would indeed be returning. We needed to return and we needed to do the right thing when we did.

\section{MOLLY \& RAQUEL}

As pre-service early childhood education professors (Kim \& Molly) we had the resources to do something meaningful both for the children in Mexican public schools as well as for our pre-service teachers. The next day I (Molly) asked our tour guide to take me to the local university, Centro Universitario de la Costa. The university, which was founded in 1994, is an affiliate of the University of Guadalajara. Not knowing exactly what I would find there, I just hoped a resource would present itself. (As has been our experience a multitude of times, fate presents us with just the right person at the right time). In this instance, a bilingual educational psychology professor, known to our guide, was walking across the university courtyard. Our tour guide waved her over and began describing the circumstances of my visit to the university.

I stood, not understanding a word they were saying, but watching the warm and accepting body language of our new Mexican colleague, Raquel Dominguez. Quickly switching to English she welcomed me to her country and to her campus. She offered us a tour. As we walked around the beautiful campus I talked to her about the experience we had at the elementary school the day before. I mentioned the feeling of shame; feeling like we were spectators. I talked about a plan to return with the intention of supporting the children in the schools in a way that was meaningful to the community in which they lived. Our new colleague responded with immediate support and began to help me identify a purposeful plan. My head was full of ideas. I discussed one thought to bring computers to the university and she gently suggested that the local elementary schools were more in need than the university. We discussed the value of teaching Spanish, rather than English. English, rather than Spanish? Was it better to bring money, or supplies? How do we find out what a particular school needs? Raquel's support and guidance seemed to be both for the plan I was beginning to outline, as well as the possibility of an ongoing relationship with us. I left the campus with my head full of ideas. I promised to keep in touch, promised to return to continue our work together.

\section{RAQUEL}

Living in Puerto Vallarta, an international tourist destination and a paradise for retirement for many foreign persons, has broadened my background on intercultural exchanges. On one side, I have realized a very valuable aspect of the American culture; a tradition and strong engagement in community service activities that may become accentuated when Americans can see the effects of poverty and underdevelopment in our Mexican communities. On the other side, the contact with other cultures makes us (Mexicans) aware - and maybe more proud of - our values, traditions, and culture. So when I first met my American colleagues, I felt their concern and solidarity. They were offering some support to our educational institutions, but quite sincerely, I thought it was a strong impression that would extinguish as soon as they were back in their university routines, especially because I thought it was only a personal experience, and I didn't realize at the time that their plan involved educational goals for their own students. But when several emails started to come and a real project began to take form I knew it was something different. It was not only to offer some help or resources, but also to get involved with our educational community and actually learn from the experience. 


\section{KIM \& MOLLY}

After landing back on U.S. soil we launched into a plan for a return trip. We discussed the information we had gathered. We talked about all that we had observed as well as the information shared by children, teachers, administrators, and our new Mexican colleagues. From our discussions, an idea for a project developed. The project included plans to invite undergraduate students to join us on a return trip to Puerto Vallarta the following year. It included incorporating a service-learning initiative into our next visit, which would support the language and literacy needs we had heard about at the school.

Eight months after we had left, an email to Raquel opened the door wider to the beginning of our working relationship. Raquel shared with us her surprise at our reconnection. She thought that, while our enthusiasm was genuine, we would return to the United States and get caught up in our personal and professional lives and forget all about the school children in Mexico. While it is true that we had quickly gotten caught up in our personal and professional lives, we simply could not forget about the school children in Mexico and our plans to support their learning.

We felt ready to begin to formalize the plans for our project. We created a formal proposal, outlining our goals and objectives, keeping a constant connection to Raquel in Puerto Vallarta. In the meantime, Raquel had enlisted the help of three colleagues she knew. Lisa, a high school teacher at a private school in Mexico who was working with honors students on a literacy project, Rosie, the principal of a public school in Las Juntas, just outside of Puerto Vallarta, and Raoul, the director of a school for children with multiple disabilities. All appeared eager to be a part of whatever this project was becoming. Email after email was sent clarifying school needs, teacher expectations, and student roles. We continued to check our assumptions about cultural boundaries and professional goals on the part of our new colleagues.

With our heartfelt proposal in hand, we began to meet with stakeholders in our university system. First, we met with the head of our department, who not only supported us professionally and academically, but was also willing to help support us financially. Next, was a visit to our Dean. Again, our proposal was met with the same enthusiasm from which it was generated. Within weeks a formalized and financed plan was approved for a return trip to Puerto Vallarta with the clear intention of participating in a Mexican service-learning project with our students.

\section{THE FORMAL PROJECT PROPOSAL}

The purpose of the initiative was twofold. First, the project would initiate and build relationships with Mexican educators (both p-6 and higher education). Second, the project would enable faculty/researchers to engage in a pilot research study, examining undergraduate students' experiences in a Mexican service-learning project. The service learning opportunity would include English and Spanish literacy development. In preparation, university students participated in seminars with faculty/researchers in which issues of cultural competence, global perspectives, ethnocentrism, and privilege were addressed. Students participated in planning of activities to be conducted with students in Mexico.

It was anticipated that this pilot project would become the foundation for an ongoing relationship with Mexican P-6 schools and would provide future service learning opportunities for pre-service teachers from the university's Education Department. Future studies/travel to Puerto Vallarta was anticipated to be offered through the International Studies Office and would be under the umbrella of a course related to global service learning/global perspectives taught by the university's early childhood faculty. The following objectives were set for the initial project trip: 
1. Students will demonstrate the ability to reflect on their professional practice.

2. Students will demonstrate the ability to synthesize their experience with a different cultural group into an understanding of what it means to be a global citizen.

3. Students will practice teaching skills, particularly skills related to teaching English language to non-English speaking students and support of Spanish language literacy to native Spanish speakers.

4. Students will participate within an educational context that is unfamiliar to them, including cultural, language, environment and setting.

5. Students will demonstrate a level of cultural competence that encompasses an understanding of issues of ethnocentrism.

6. Students will complete a series of reading assignments and discussion seminars both in preparation for travel, as well as during and post travel.

7. Faculty researchers will create the necessary contacts to ensure viability for upcoming terms (the intent is that this will be an ongoing J-term and May-term offering).

\section{IMPLEMENTATION OF THE SERVICE-LEARNING-PROJECT-SPRING 2006}

On March $9^{\text {th }}$ we set out to Puerto Vallarta with 10 undergraduate students and the two daughters who had made the previous trip. We had spent the previous months making connections with schools and arrangements for travel and lodging. Through emails we scheduled initial visits, classroom experiences and planning meetings. By the time we were ready to travel we had a 7-day schedule full of valuable visits.

One of our new connections was a private school teacher who was raised in the U.S. and lived in Mexico. She was instrumental in making meaningful connections for us with a variety of school settings. She was also the National Honors Society leader at the American School in Puerto Vallarta and was working with her students to develop a literacy project for the local public schools called Leer y Crecer (Read and Grow). She welcomed our students to participate in the project and set up literacy training for our students, which they attended early in the trip. With the help of our English speaking colleagues we were able to establish a schedule that gave us a sense for the differences in educational settings and needs in Puerto Vallarta. Additionally, these contacts helped to establish meaningful relationships with school officials. The information gathered with school officials provided us with a valuable perspective needed to effectively interact in the Mexican schools, and information about the politics and public relations inside the school, which was critical to our ability to support and understand the school culture. This information helped us to take into consideration the issues that may lead to teacher resistance as well as to ensure that teachers had the necessary information to develop a comfort level to support the project more than to feel it is imposed upon them. Along with educational policy we also learned about the circumstances of special education institutions in Puerto Vallarta and their specific material and educational needs.

The Pensador Mexicano Public Elementary School is located in a suburb of Puerto Vallarta. It has classrooms from first to sixth grade (included in Mexican elementary level), attended by girls and boys. Each class has one teacher in charge of the entire curriculum, which includes Spanish, Math, Natural Sciences and Social Studies. Children and teachers are at school from 8 to 12:30 Monday through Friday. An afternoon session offers school from 1-5:30 for an entirely different student body and group of faculty. All teachers have undergraduate training as elementary teachers, (some have training in a variety of other grades), other advanced training programs (i.e. special education) and multiple years of teaching experience.

The Centro de Atención Múltiple (CAM) is designed to support the educational needs of children with special needs from pre-school to 15 years of age. In most cases the children attend a "regular" school in the morning and attend the CAM in the afternoon for special education services. This educational design is intended to support the child's performance in the "regular" classroom and/or compensate for specific needs. The CAM provides services for children with a wide range of needs from perceptual deficit (blindness, deafness, etc.), intellectual or motor skill deficit, to a variety of other development syndromes. Special education teachers have frequently added to their regular teacher training through specialized training in particular areas of special education. 
Our general impression upon visiting was that despite our pre-conceived ideas, both institutions worked in apparently smooth ways, and are valued by children, parents, teachers and the community as good opportunities for educational development.

\section{THOUGHTS FROM RAQUEL}

From what has happened since our initial meeting, I share some thoughts:

1) Mexican educators, including myself, are very proud of our programs, including the theoretical principles and the materials produced. We are not expecting from "the outside" to improve our programs or to provide new approaches to our situations, but rather, the resources and/or the training we need to better perform those programs. Especially in early education, our preschool and early primary school programs have been improved, discussed in several forums and have become part of our teacher's identity. The programs are more oriented to process than to content, and have the goal to attend to the integral growth of the students, no only their cognitive side, but the social and the emotional development. We are proud also of the public educational system that - by law - is "libre, laica, gratuita y obligatoria" and covers the majority of our population, giving almost every child in our country the opportunity to go to school for at least 10 years.

2) We are also very proud of our history, our culture and traditions, and that is something we like to show, share and maybe transmit to other cultures. I include here some cultural aspects like the way we demonstrate affection, the importance and the physical contact we easily establish in human relations, or the opening of our hearts to new people that we express by "mi casa es tu casa" (my home is yours).

3) Because of the two ideas above, some teachers will resist or do not trust at the beginning the influence of a foreign group of teachers and students, maybe because they fear they will try to judge their job or to dictate new standards. That was the case with some of the teachers at the public elementary school. But on the contrary, the visiting students and teachers were very careful to avoid presenting themselves as experts, and were very open and sensitive to the context, the guidance I and my colleagues could give, and the territory of the Mexican teachers. At the moment all the teachers, including the ones that resisted at the beginning, are willing to receive new visits and thankful for the opportunity they are offered with this project. An inter-cultural approach in education means not only to respect the difference between cultures, but to value them positively and openly (Rodríguez Rojo, 1995).

4) The apparent difficulty of the American students not speaking Spanish becomes a factor that facilitates the relationship in the sense that Mexican students and teachers can feel they have something to teach, where they are the experts, and have something important to share. It seems to me that at the CAM school that was an important aspect that makes everyone put extra effort in communicating. The good attitude about learning the language is also a good example for the kids and teachers that realize learning English could be an important educational goal in this region, but sometimes feel intimidated or uncomfortable making mistakes.

\section{FINAL THOUGHTS - KIM \& MOLLY}

Our most profound finding has been that the more we know about Mexican education, the more we find links and similarities with the problems, the theoretical issues and the processes taking place in the United States. We have learned foremost that regardless of specific cultural ways, true understanding reinforces the reality that we are all global citizens.

This service-learning initiative is foundational to the programmatic direction our university program, the unified early childhood studies program, has been moving toward for some time. Specifically, the desire to provide opportunities for students to travel outside of the United States in order to explore other cultures, examine their own assumptions, and grow as pre-service teachers. While it is difficult to provide students who come from, and attend university in, predominantly white settings, it is possible to provide pre-service teachers with short-term field experiences, engaging them in guided reflection, in order to have an effect on their attitudes (Wolfe, 1996). "Few educators today are unaware of the formidable educational challenges presented by the changing linguistic and 
ethnic composition of the nation's public school population" (Wilhelm, Cowart, Hume, \& Rademacher, 1996, p.48). Some researchers suggest that the way to mitigate resistance to antiracism training is to provide a race-focused multicultural education opportunity in which the participants can reflect on their own racial identity and the effect of racism. They propose a course that would help students question their misinformation, and to develop an understanding of their own racial identity (Lawrence \& Bunche, 1996). White people with more fully developed racial identities have a greater chance of being successful in mixed racial settings (Helms, 1990, in Lawrence \& Bunche, 2996). It is to this end that we dedicate ourselves.

\section{REFERENCES}

1. Case, K. A. \& Hemmings, A. (2005). Distancing strategies: White women preservice teachers and antiracist curriculum. Urban Education, 40(6). Pp. 606-626.

2. Causey, V.E., Thomas, C.D. \& Armento, B.J. (2000). Cultural diversity is basically foreign to me: The challenges of diversity for preservice teacher education. Teaching and Teacher Education, 16, pp. 33-45.

3. Helms, J.E. (1990). Black and White Racial Identity: Theory, Research and Practice. Westport, CT: Greenwood Press.

4. Lawrence, S.M. \& Bunche, T. (1996). Feeling and dealing: Teaching white students about racial privilege. Teaching and Teacher Education. 12, pp. 531-542.

5. Rodriguez Rojo, M. (1995). La Educacion para la Paz y el interculturalismo como tema transversal. Barcelona, Oikos.

6. Wilhelm, R.W., Cowart, M.F., Hume, L.M., \& Rademacher, J.A. (1996). The effects of a professional development institute on preservice teachers' perceptions of their intercultural knowledge and sensitivity. The Teacher Educator: The Official Organization of the Indiana Association of Teacher Educators, 32(1). Pp. 48-61.

7. Wolffe, R., \& Falk-Ross, F.C. (2002). Impact of early clinical experiences on student attitudes about diversity. Journal of Early Childhood Teacher Education, 23(2), 157-165.

8. Wolffe, R. (1996). Reducing preservice teachers' negative expectations of urban students through field experience. Teacher Education Quarterly, (WTR). Pp. 99-107. 
NOTES 